\title{
Method of assessing the reproducibility of blood flow measurement: factors influencing the performance of thermodilution cardiac output computers
}

\author{
J D MACKENZIE,* NEVA E HAITES, $\dagger$ J M RAWLES $\dagger$ \\ From the ${ }^{\star}$ Department of Anaesthetics, Aberdeen Royal Infirmary, and $†$ Department of Medicine, University \\ of Aberdeen, Foresterhill, Aberdeen
}

SUMMARY Measurements of blood flow by three different makes of thermodilution cardiac output computer in an artificial circulation were analysed by linear regression against absolute flow measured by timed blood volume collection. For each computer the horizontal distance between the $95 \%$ confidence limits for a single prediction was calculated at a standard flow rate of 5 litres per minute. This measurement represents the range of flow rates that could give rise to an identical measurement and provides a summary of the reproducibility of the computer's results and its ability to detect a change of flow rate.

This measurement was used to evaluate the effect on each computer's performance of pulsatile or continuous flow, injectate volume, and injectate temperature. With continuous flow the optimum results were $1 \cdot 8,0.85$, and 0.85 litres per minute and with pulsatile flow they were $1 \cdot 3,1 \cdot 05$, and 1.65 litres per minute. There was generally a deterioration in performance when pulsatile flow was evaluated. Under the conditions of the experiment optimum performance in both flow modes was obtained with $5 \mathrm{ml}$ of ice cold injectate, but these findings cannot necessarily be extrapolated to the clinical situation.

With pulsatile flow the overall range of blood flows that could give rise to identical measurements were for each computer $2 \cdot 0,1 \cdot 5$, and $3 \cdot 1$ litres per minute, corresponding to 40,30 , and $62 \%$ changes of the standard flow rate of 5 litres per minute.

There is no method of determining cardiac output directly. Thermodilution is the most widely used of the indirect and invasive methods of measuring cardiac output based on the Fick principle. There are varying estimates of the reproducibility of thermodilution and conflicting reports on the factors that influence it. ${ }^{1}$ We have therefore assessed the accuracy and reproducibility of thermodilution in an artificial circulation using absolute flow rates measured by timed blood volume collection as the reference standard.

Measurements were made by three cardiac output computers simultaneously, with continuous or pulsatile flow at several flow rates, and with various vol-

Requests for reprints to Dr John M Rawles, University Department of Medicine, Aberdeen Royal Infirmary, Foresterhill, Aberdeen AB9 2ZB.

Accepted for publication 17 September 1985 umes of ice cold or room temperature injectate. For each cardiac output computer measurements of blood flow were correlated with absolute flow rate. The resulting regression equations were used to predict the measurements and their $95 \%$ confidence limits that would have been expected at a standard flow rate of 5 litres per minute. The reduction of flow rate necessary for a single measurement to fall outside these confidence limits with $95 \%$ certainty was then calculated. This figure was used to summarise the reproducibility of the measurement and the computer's ability to detect a change of flow rate, since in clinical practice the ability to recognise a change of cardiac output is as important as measurement of its absolute value.

\section{Methods}

ARTIFICIAL CIRCULATION

Figure 1 shows the components of the artificial cir- 


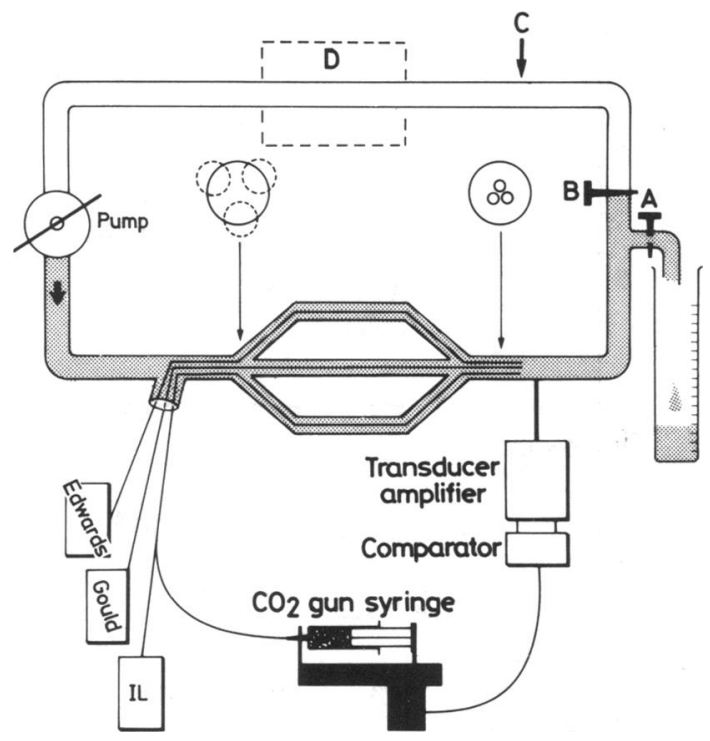

Fig. 1 Design of artificial circulation. $A$ and $B$ are taps.

culation which are connected by polyvinyl chloride tubing. A Sands 7400 pulsatile/constant flow pump was provided at " $D$ " and a Cobe Opriflow II bubble oxygenator and heat exchanger connected to a Radiometer Type VTS 13 water heater maintained circulating blood temperature between $36^{\circ} \mathrm{C}$ and $37 \cdot 5^{\circ} \mathrm{C}$. The system was filled with eight bags of packed red cells $(200 \mathrm{ml}$ per bag), polygeline (Haemaccel) $2000 \mathrm{ml}$, normal saline $800 \mathrm{ml}$, and silicone antifoam powder to give a circulating fluid volume of 4.4 litres from which all air bubbles were removed. The pump output passed a side arm through which three thermodilution catheters entered, their proximal ports lay $4 \mathrm{~cm}$ upstream of a trifurcation of the circulation, each channel contained a thermodilution catheter and carried a third of the total flow for a distance of $6 \mathrm{~cm}$ before being reunited $14 \mathrm{~cm}$ proximally to the thermistors in the catheter ends. This configuration was adapted from that of Bilfinger et $a^{2}$ and was designed to avoid a stagnant pool and provide optimal mixing of the indicator by disturbing laminar flow, and also to allow the flow rate to be measured by all three thermodilution computers simultaneously. The distal ends of the thermodilution catheters were fixed in the centre of the flow with their respective thermistors facing outwards; the diameter $(1.25 \mathrm{~cm})$ and length of tubing at this point ensured laminar flow at the flow rates being used.

\section{THERMODILUTION}

Table 1 lists the thermodilution cardiac output computers and the catheters with which they were used. All three computers provide a digital read out of "cardiac output" based on automatic computation of the area under the temperature-time curves; Table 1 also indicates the different methods of calculating this area. In the Instrumentation Laboratories computer the curve is displayed on a monitor; in the artificial circulation the curve invariably had a satisfactory appearance and was not recorded.

The injectate was $5 \%$ dextrose solution, and when it was used at room termperature it had been stored in the room for at least $\mathbf{1 6}$ hours. Ice cold injectate was taken from a $500 \mathrm{ml}$ bottle of $5 \%$ dextrose that had been kept in an ice bucket for at least four hours and was drawn into syringes that had been kept in ice for at least 30 minutes. The loaded and capped syringes were then stored in ice for at least 30 minutes before use and injected within five seconds of removal from ice. Injectate volumes of 3, 5, and $10 \mathrm{ml}$ were used with all thermodilution computers, but no results for $3 \mathrm{ml}$ injectate are given for the Instrumentation Laboratories computer since it is not designed to operate at this volume when a $7 F$ catheter is used. The Gould computer gave frequent "out of range" reports with $5 \mathrm{ml}$ injectate at high flow rates.

All injections were made with a carbon dioxide powered syringe driver (OMP Thermodilution Injector, Model 372000). During pulsatile flow the pressure waveform was monitored by an electromagnetic transducer (Druck, model PDCR75), amplified (DC amplifier Roch 1-222), and the signal was used to trigger the syringe injector at the same point in the pump cycle for each measurement.

The injectate temperature was measured by an in-

Table 1 Thermodilution cardiac output computers, thermodilution catheters, and computation method

\begin{tabular}{|c|c|c|}
\hline Cardiac output computer & Thermodilution catheter & Cardiac output computation \\
\hline Instrumentation Laboratories IL701 & IL 7F with in-line temperature probe & $\begin{array}{l}\text { Area under curve until return to baseline } \\
\text { temperature }\end{array}$ \\
\hline Edwards 9520A & Swan-Ganz 93A-131-7F & $\begin{array}{l}\text { Area under curve to } 30 \% \text { of peak temperature } \\
\text { change } \times 1.22 \text { for tail }\end{array}$ \\
\hline $\begin{array}{l}\text { Gould SP1435 with SP2009B } \\
\text { printer/recorder }\end{array}$ & Gould $7 F$ with in-line temperature probe & $\begin{array}{l}\text { Area under curve to } 87.5 \% \text { of peak temperature } \\
\text { change }+ \text { area under downslope from } \\
87 \cdot 5-31 \cdot 25 \% \text { peak }+55.55 \% \text { of preceding } \\
\text { area }\end{array}$ \\
\hline
\end{tabular}


line temperature probe on the Instrumentation Laboratories and Gould computers. For the Edwards computer the temperature of the water bath containing the loaded injectate syringe was measured directly.

Measurements were made simultaneously on all three cardiac output computers at several flow rates after injection of 3,5 , and $10 \mathrm{ml}$ volumes of ice cold and room temperature dextrose solution.

\section{ABSOLUTE FLOW MEASUREMENT}

To measure absolute flow rate, tap " $A$ " was opened, tap " $B$ " was closed (Fig. 1), and the time taken to fill a measuring jar was noted with a stop watch; an average of 4.4 measurements was made at each flow rate. The mean coefficient of variation was $0.8 \%$ for continuous flow measurements and $2.6 \%$ for pulsatile flow.

\section{STATISTICAL METHODS}

For each computer the mode of blood flow, injectate temperature, and injectate volume were analysed by linear regression of computer measurement against absolute flow rate. The predicted measurement $\hat{y} \pm$ standard error of prediction at a standard flow rate of 5 litres per minute was obtained by substitution in the regression equation. ${ }^{3}$ The graphical results show the regression line together with $95 \%$ confidence limits for a single prediction. The horizontal distance, delta, between the confidence limits at a flow rate of 5 litres per minute was calculated and gave a reduction of flow needed for a single measurement at the new flow rate to fall with $95 \%$ certainty outside the confidence limits for measurements at a flow rate of 5 litres per minute. Alternatively delta may be considered as the range of flow rates that could give rise to identical measurements $(p>0.05)$. Delta may also be expressed as a percentage of the standard flow rate $(\mathrm{D} \%)$.

\section{Results}

\section{THERMODILUTION}

Figures 2-5 show the average estimates of blood flow at different flow rates in three different makes of thermodilution machine and at three different injectate volumes. In Figs. 2 and 3 flow is continuous, and in Figs. 4 and 5 flow is pulsatile. Table 2 gives the regression equations derived from these results together with measurements predicted at a standard flow rate of 5 litres per minute.

\section{EFFECT OF IN JECTATE VOLUME}

With continuous flow and injectate at room temperature, $10 \mathrm{ml}$ injectate resulted in a larger error of prediction than one of $3 \mathrm{ml}$ or $5 \mathrm{ml}$. The predicted

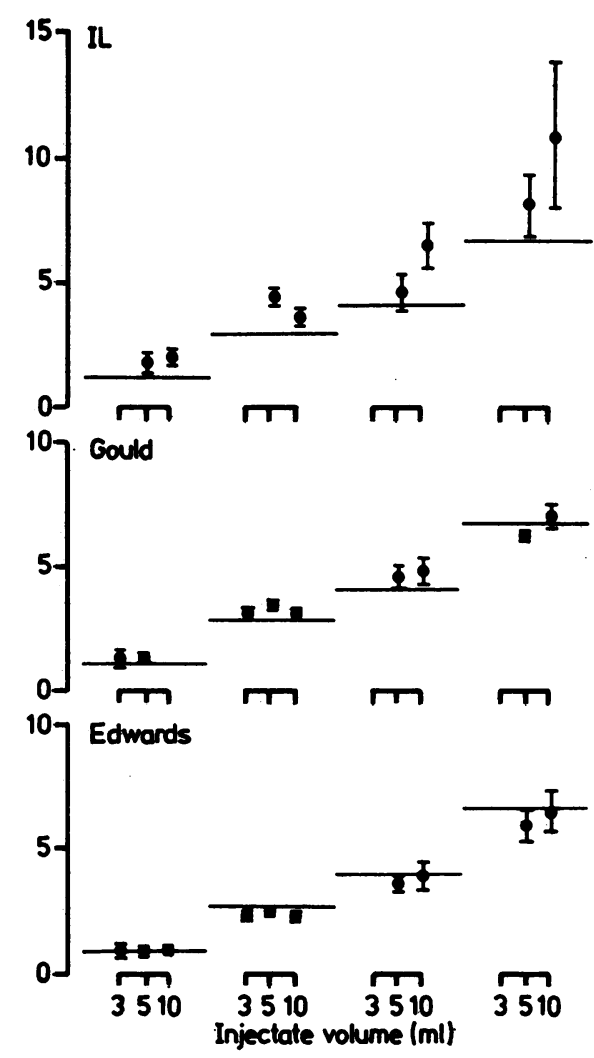

Fig. 2 Mean \pm 1 standard deviation of blood flow measurement by three different thermodilution cardiac output computers at various absolute flow rates and various injectate volumes. Value of absolute flow rates is indicated by horizontal lines. Continuous flow, injectate at room temperature.

measurement at a flow rate of 5 litres per minute was also larger in each case at $10 \mathrm{ml}$, resulting in improved accuracy with the Edwards computer which underestimated the measurements and reduced accuracy with the IL and Gould computers which overestimated the measurements.

With pulsatile flow and injectate at ice temperature, a $5 \mathrm{ml}$ injectate gave least variability with Gould and IL computers but a $10 \mathrm{ml}$ injectate gave least variability with the Edwards computer; there was no consistent effect on accuracy. With continuous flow and ice cold injectate and with pulsatile flow and room temperature injectate there was no consistent effect on either accuracy or variability.

\section{EFFECT OF PULSATILE FLOW}

Pulsatile flow produced a pronounced increase in the variability of measurements, with the standard error of the prediction being approximately double that with continuous flow in most cases. The accuracy of 


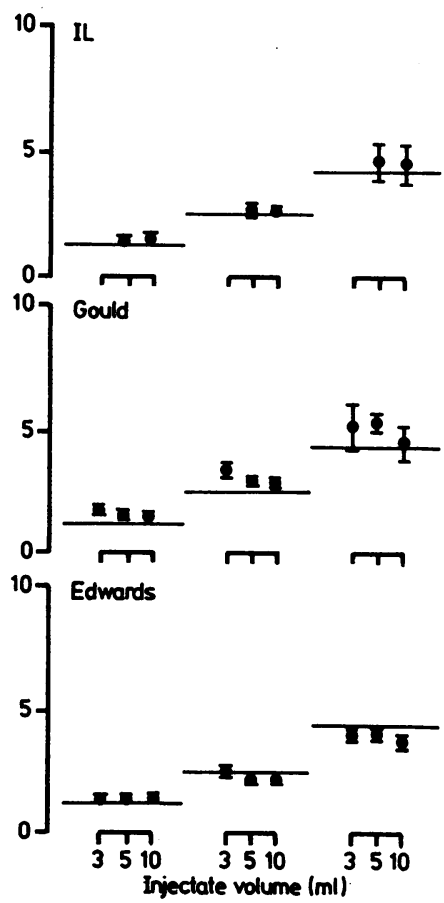

Fig. 3 As in Fig. 2 but with ice cold injectate.

the measurements was reduced with flow rates being overestimated, sometimes very substantially.

\section{EFFECT OF INJECTATE TEMPERATURE}

Use of ice cold injectate instead of injectate at room temperature reduced the variability and improved the accuracy of the IL and Edwards but not the Gould computer during continuous flow measurements. Use of ice cold injectate with pulsatile flow reduced variability but led to a further substantial overestimation of flow rate, except in the case of the IL computer where there was a slight reduction in the gross overestimate present with pulsatile flow.

\section{OPTIMUM AND OVERALL PERFORMANCE}

With pulsatile flow the highest correlation coefficient and the lowest percentage horizontal distance between confidence limits $(\mathrm{D} \%)$ were obtained by each computer with a $5 \mathrm{ml}$ ice cold injectate. Under these conditions the lowest standard error of prediction was $\mathbf{0 . 4 8}$ litres per minute, that is $9.6 \%$ of the flow rate of 5 litres per minute used in the prediction. Figures 6 to 8 show the regression lines relating measurements made by the three cardiac output computers to flow rates together with $95 \%$ confidence limits for a single prediction when $5 \mathrm{ml}$ of ice cold solution was injected. The $95 \%$ confidence limits at a flow rate of 5 litres

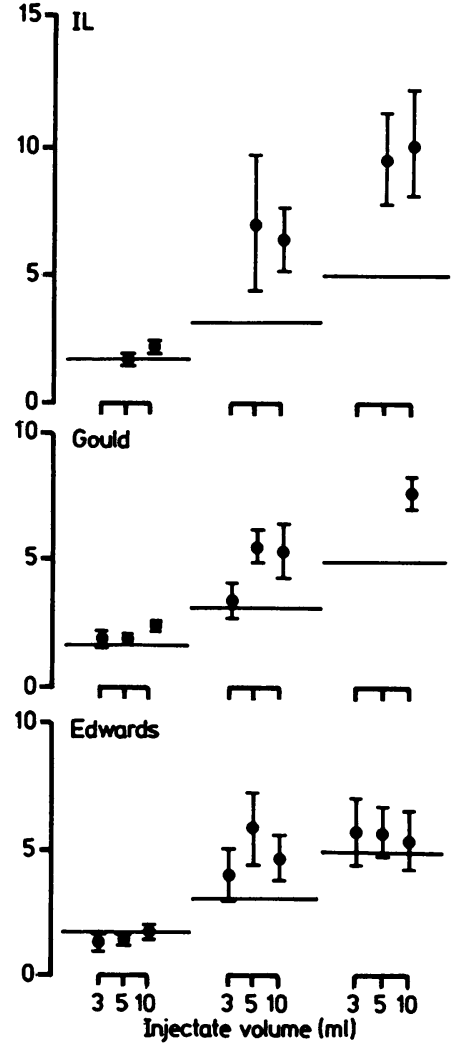

Fig. 4 As in Fig. 2 but with pulsatile flow, and injectate at room temperature.

per minute are $\pm 1.3, \pm 1.0$, and \pm 1.5 litres per minute, and the percentage horizontal distance between confidence limits $(\mathrm{D} \%)$ is $26 \%, 21 \%$, and $33 \%$ of the standard flow rate for IL, Gould, and Edwards cardiac output computers respectively.

Injectate temperatures and volumes giving the most accurate predictions of pulsatile flow rate were different for each computer. The predictions were $9 \cdot 47,5 \cdot 29$, and 5.77 litres per minute for IL, Gould, and Edwards computers and the corresponding percentage horizontal distances between confidence limits were 26,66 , and $87 \%$ respectively.

During pulsatile flow with injectate volumes of 5 or $10 \mathrm{ml}$ at room or ice temperature the percentage horizontal distances between confidence limits were $40 \%, 30 \%$, and $62 \%$ for IL, Gould, and Edwards computers. These values summarise each computer's overall performance and correspond to a range of blood flows of 2.0, 1.5, and 3.1 litres per minute which could give rise to identical measurements (Figs. 9-11). 


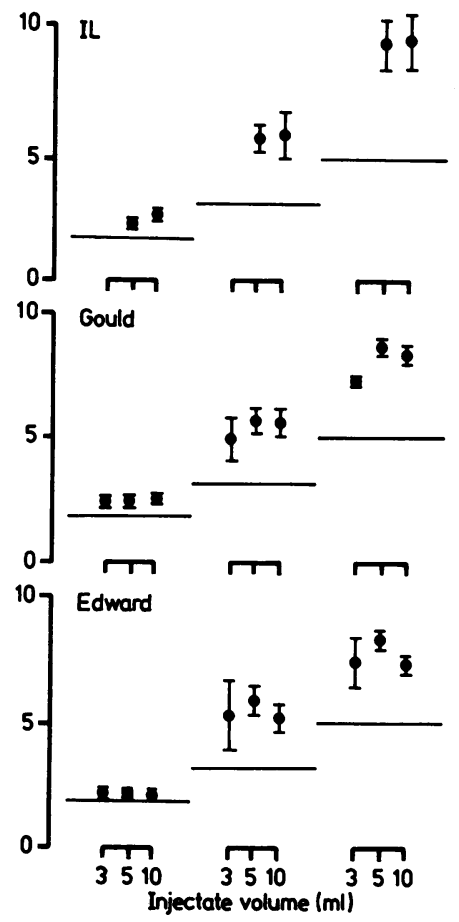

Fig. 5 As in Fig. 2 but with pulsatile flow, and ice cold injectate.

\section{COMPARISONS BETWEEN CARDIAC OUTPUT COMPUTERS}

With pulsatile flow all three cardiac output computers overestimated absolute flow rate but when compared with each other accuracy is apparently greatly improved. This suggests that the factors resulting in loss of accuracy with pulsatile flow affect all three computers similarly. Table 3 gives a correlation matrix based upon 63 simultaneous measurements made with ice cold and room temperature injectate of 5 and $10 \mathrm{ml}$.

\section{Discussion}

\section{MEASUREMENT OF CARDIAC OUTPUT BY FICK}

The direct Fick method is the reference method for measuring cardiac output in man. ${ }^{4}$ This technique requires the measurement of partial pressures of oxygen and carbon dioxide in expired air, and measurement of oxygen saturations in arterial and mixed venous blood over several minutes. Important sources of error are incomplete gas collection, inadequate mixed venous sampling, and a non-steady state. ${ }^{5}$ Right heart catheterisation is required as well as arterial sampling since the only satisfactory source of mixed venous blood is the pulmonary artery. Unless the patient is intubated a high degree of patient cooperation is required to get a complete gas collection. The quoted error of the method is about $10 \%,{ }^{6}$ but although the median difference in duplicate readings was $8.6 \%$ the results were skewed and $13 \%$ of readings had differences greater than $19 \%$.

The Fick principle, with its assumption of steady state conditions, is poorly adapted to measuring pulsatile flow with oxygen as a dilutant; oxygen enters the circulation phasically with respiration. The latter problem is overcome by dye and thermodilution methods in which a known quantity of marker is injected into the circulation. The underlying theory generally assumes continuous flow ${ }^{8} 9$ but a mathematical proof of the validity of applying the method to pulsatile flow has been given. ${ }^{10}$

\section{DYE DILUTION}

The direct Fick method for measuring-cardiac output was superseded by dye dilution, and while there appear to be no systematic differences between the two techniques, individual differences may be pronounced. Thus 12 of 53 comparisons varied by $>25 \%{ }^{11}$ six of 48 comparisons differed by $>25 \%,{ }^{12}$ and 26 of 105 comparisons deviated by $>20 \%$ from the line of identity. ${ }^{13}$ The total dose of dye limits the number of measurements that may be made in any individual.

\section{THERMODILUTION}

Thermodilution has now supplanted dye dilution as the standard method of cardiac output measurement. ${ }^{14}$ The advantage over dye dilution is that the marker is innocuous so there is virtually no limit to the number of measurements that may be made, and recirculation is not a major problem. ${ }^{1}$ Difficulties result from the use of heat as a marker, however, because an unknown quantity of thermal indicator may be lost from the injectate before it enters the circulation, ${ }^{15}$ and subsequently from the circulation through the vessel wall. ${ }^{16}$ Intrathoracic blood temperature may fluctuate due to a phasic exchange of heat with air in the lungs ${ }^{17}$ and a variable return of cooler venous blood from the periphery. ${ }^{18}$ The former problem is overcome by the inclusion of a correction factor in the calculation of cardiac output to allow for loss of cold injectate, which can be minimised by using injectate at room temperature. ${ }^{19}$ Reducing the temperature differential between blood and injectate, however, increases the effect of "noise" in the baseline temperature measurement on the calculation of the area under the temperature time curve.

When they introduced the technique of thermodilution Ganz et al compared it with dye dilution 
Table 2 Correlation coefficients and regression equations relating flow rate and its estimation by three different makes of thermodilution cardiac output computer

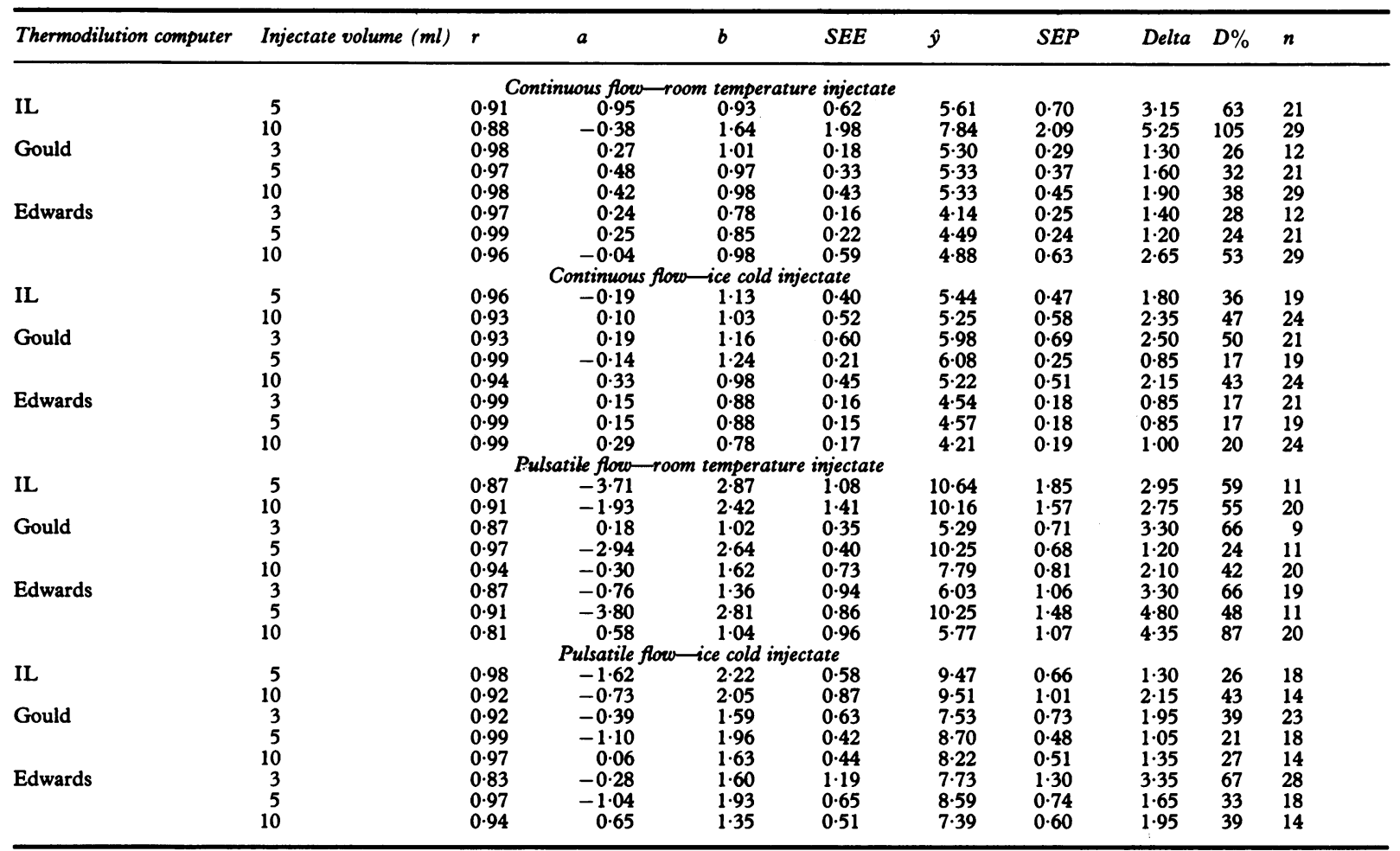

$r$, correlation coefficient for which the regression equation is $y=a+b x$ where $x$ is flow rate, $y$ is cardiac output computer measurement; SEE, standard error of the estimate, $\hat{y}$ is predicted value of measurement for $x=5$; SEP, standard error of prediction; delta, horizontal distance between $95 \%$ confidence limits at an upper flow rate of $5 ; D \%$, delta $\times 100 / 5$. Units are litres per minute.

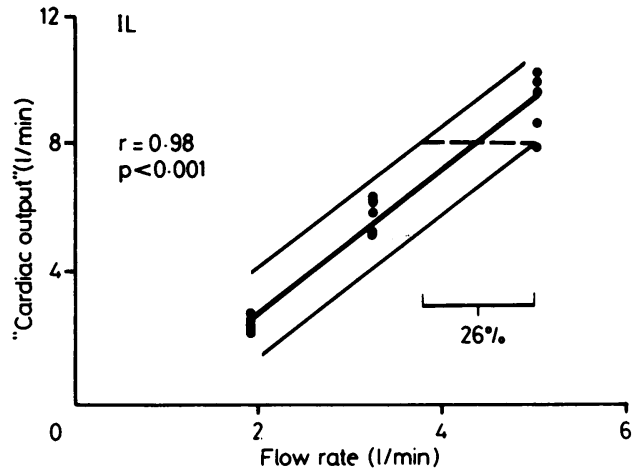

Fig. 6 Regression of individual measurements of blood flow by IL thermodilution cardiac output computer against absolute blood flow together with $95 \%$ confidence limits for a single prediction. Horizontal distance between confidence limits is expressed as a percentage of standard flow rate of 5 litres per minute. Optimal results with $5 \mathrm{ml}$ ice cold injectate. In Figs. 6 to 11 scales for axes differ to accommodate overestimation of flow rate by all three cardiac output computers.

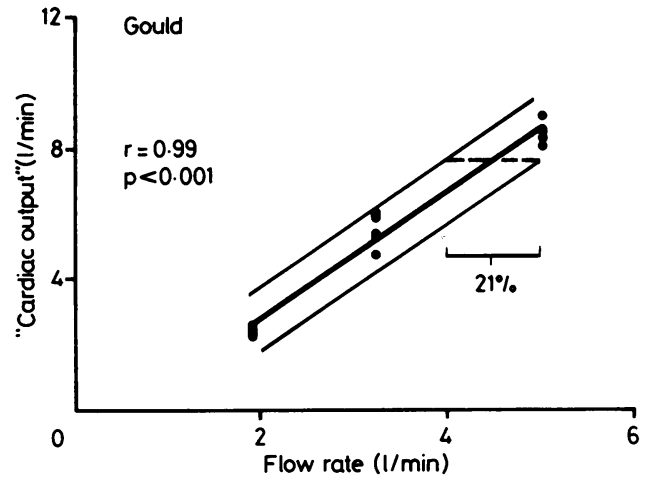

Fig. 7 As in Fig. 6 but for Gould computer.

and the correlation coefficient was 0.96 with a standard error of the estimate of 0.36 litres per minute or $7 \%$ of the mean cardiac output which was about 5 litres per minute. ${ }^{20}$ In clinical studies other groups have obtained coefficients of correlation between thermodilution and dye dilution methods ranging 


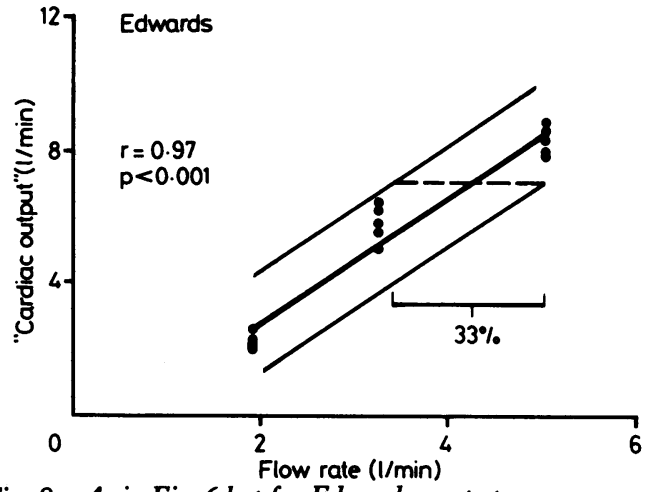

Fig. 8 As in Fig. 6 but for Edwards computer.

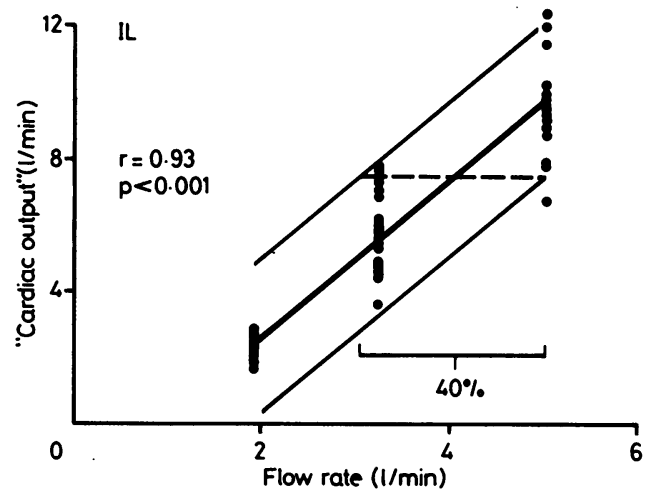

Fig. 9 As in Fig. 6 but showing overall results for $5 \mathrm{ml}$ and $10 \mathrm{ml}$ of ice cold or room temperature injectates and an $I L$ computer.

from 0.90 to $0.99,{ }^{21-25}$ and correlation coefficients were 0.70 and 0.93 when the thermodilution method was compared with direct Fick. ${ }^{26} 27$

Fischer et al used an injectate of cold indocyanine green for simultaneous measurement of cardiac output by thermodilution and dye dilution in cardiothoracic patients in the operating theatre and

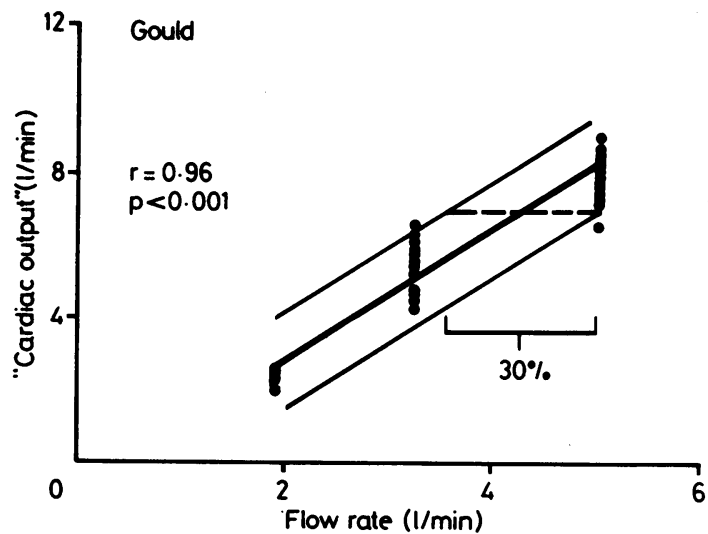

Fig. 10 As in Fig. 9 but for a Gould computer.

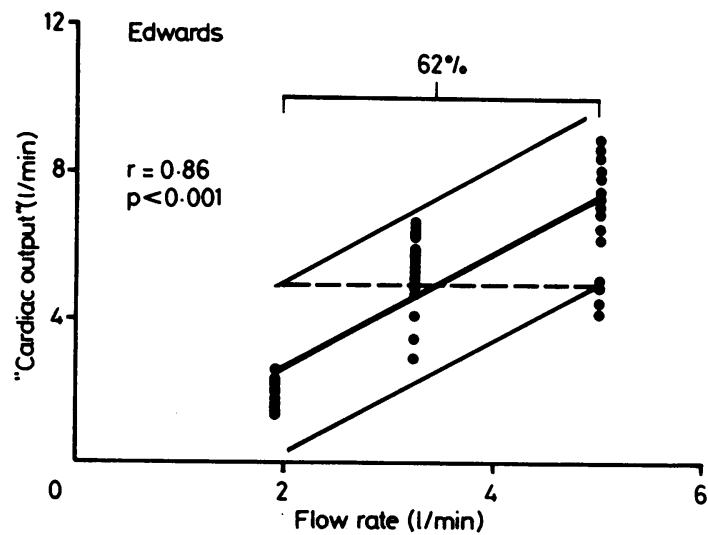

Fig. 11 As in Fig. 9 but for an Edwards computer.

intensive care unit. ${ }^{28}$ By duplicating all measurements they were able to estimate the proportions of total variance that could be attributed to flow change between measurements, random error, and calibration error of dye and thermodilution sep-

Table 3 Correlation matrix giving correlation coefficients and prediction of measurement and standard error of prediction based on 63 simultaneous estimates of pulsatile flow rate by three different makes of thermodilution cardiac output computer with ice cold and room temperature injectates of 5 and $10 \mathrm{ml}$

\begin{tabular}{|c|c|c|c|c|}
\hline$y$ & Flow rate & $I L$ & Gould & Edwards \\
\hline $\begin{array}{l}x \\
\text { Flow rate } \\
\text { IL } \\
\text { Gould } \\
\text { Edwards }\end{array}$ & $\begin{array}{l}r \\
\hat{y}(\text { SEP) } \\
0.933 \\
3.02(0.45) \\
0.961 \\
3.20(0.34) \\
0.859 \\
3.48(0.64)\end{array}$ & $\begin{array}{l}0.933 \\
9.80(1.14) \\
- \\
\overline{0.961} \\
5.52(0.87) \\
0.869 \\
6.22(1.55)\end{array}$ & $\begin{array}{l}0.961 \\
8.31(0.66) \\
0.961 \\
4.65(0.65) \\
\overline{0.941} \\
5.56(0.79)\end{array}$ & $\begin{array}{l}0.859 \\
7.31(1 \cdot 17) \\
0 \cdot 869 \\
4 \cdot 18(1 \cdot 11) \\
0.941 \\
4 \cdot 47(0 \cdot 76)\end{array}$ \\
\hline
\end{tabular}

$r$, correlation coefficient for which the regression equation is $y=a+b x$ where $x$ is flow rate, and $y$ is cardiac output computer measurement; $\hat{y}$ is predicted value of measurement for $x=5 ; S E P$, standard error of prediction. Units are litres per minute. 
arately. In the intensive care unit, where patients were haemodynamically more stable than in the operating theatre, flow change was $5 \%$ between measurements, reproducibility was $10 \%$ and $11 \%$, and the random error of a single measurement by dye dilution and thermodilution was $5.5 \%$ and $6.5 \%$ respectively. This study, however, and the others cited, all have the drawback that there is no absolute yardstick of cardiac output measurement, and the comparability of results from two related techniques does not rule out the occurrence of a systematic error that affects both. The correlation between two indicator dilution techniques may be closer than that between thermodilution and the direct Fick method with which thermodilution has less often been compared.

An electromagnetic flowmeter has been used to measure cardiac output in dogs and calves, and the correlation coefficients compared with thermodilution were 0.97 and 0.98 , with standard errors of the estimate of 0.45 and 0.75 litres per minute respectively. ${ }^{29}$

\section{STATISTICAL ASPECTS OF \\ REPRODUCIBILITY}

The correlation coefficient is commonly used to express the relation between measurements of cardiac output made by two different methods. Its value is, however, influenced by the range of values studied, so that it may be substantially increased by a single outrider. The standard error of the estimate gives more information about the scatter of values around the regression line, and hence the confidence of a prediction, than the $r$ value. The standard error of the estimate, however, is closely related to the correlation coefficient and has some of its limitations. Unfortunately, in published reports on cardiac output measurement even the standard error of the estimate is not always quoted or there is insufficient raw data to make meaningful comparisons between different reports.

We have used the standard error of the prediction as a means of expressing variability. ${ }^{3}$ It increases as the predictor variable moves away from its mean value, and its calculation at a standard flow rate of 5 litres per minute allows direct comparison of variability measured under different experimental conditions. By itself, the standard error of the prediction, or any other measure of variability such as the standard error of the estimate, is insufficient to describe the performance of a method for measuring cardiac output since an instrument which gives the same measurement whatever the flow rate would have low variability but would not fulfil its clinical function of measuring a change of cardiac output.

The standard error of the prediction is approxi- mately one quarter of the vertical distance between $95 \%$ confidence limits for a single prediction. The horizontal distance between confidence limits has been used in this paper to provide a summary of the overall performance of the cardiac output computers. It is related to the vertical distance by the slope of the regression line relating measurement and flow rate, thus overcoming the objection to the use of a measure of variability by itself. In the case of an instrument that gives the same result whatever the flow rate its value would be infinitely large. The horizontal distance between confidence limits represents the range of flow rates that could give rise to the same measurement. It is equal in value to the vertical distance between confidence limits if the regression is reversed and flow rate is regressed on its measurement. It is not the same as the minimum change of flow that may be recognised; providing the slope of the regression line is not zero any change of flow rate may be detected if a sufficient number of measurements is made.

IN VITRO VALIDATION OF THERMODILUTION

Bilfinger et al evaluated the performance of an Edwards cardiac output computer in an in vitro model using a continuous flow roller pump. ${ }^{2}$ With a $10 \mathrm{ml}$ injectate at room temperature the mean accuracy of estimates of six flow rates was within $7 \%$ with a coefficient of variation of $5.4 \%$. Neither the volume or temperature of the injectate had any influence on their results. In our circulation model, adapted from that of these workers, the Edwards computer measured four flow rates with a mean accuracy of $3.2 \%$ and a coefficient of variation of $9.6 \%$, the total error with our model under conditions of continuous flow being very similar in magnitude to that of Bilfinger et al.

Powner and Snyder compared six thermodilution cardiac output systems in vitro using a pulsatile pumping unit, ${ }^{30}$ but none of the models we studied was included. The standard deviations of the measurements at a flow rate of 4.26 litres per minute (the nearest value to our standard flow rate of 5 litres per minute) varied from 0.046 to 0.11 litres per minute with room temperature injectate and 0.052 to 0.19 litres per minute with ice cold injectate. The same pulsatile flow rate was under or overestimated by -8.7 to $+9.2 \%$ with room temperature injection and -0.2 to $+23.5 \%$ with iced injectate. Reproducibility and accuracy were generally better than in our circulatory model but no clear relation with our own results emerges, and the most important conclusion may be that the operating conditions for optimal reproducibilty or accuracy in one experiment may not be the same as in another. By 
implication, the results in our artificial circulation may not be applicable to the clinical situation.

\section{INJECTATE TEMPERATURE}

Shellock et al compared thermodilution cardiac output measurements using ice cold and room temperature injectates and concluded that the measurements and their variability were similar by both methods, both in critically ill subjects with a normal body temperature ${ }^{31}$ and in hypothermic surgical patients. ${ }^{32}$ Other groups have shown that the use of room temperature rather than ice cold injectate increased the variability of the results, but the increase in the coefficient of variation has not always been statistically significant. ${ }^{33} 34$

Our experiments showed that the use of ice cold injectate generally reduced the variability of measurements compared with that when the injectate was at room temperature, as would be expected theoretically. With continuous flow and ice cold injectate, the pooled measurement prediction at a flow rate of 5 litres per minute was overestimate by only $2 \cdot 2 \%$, indicating that the correction factors for loss of marker from the injectate are more or less correct in our experimental model.

\section{EFFECT OF PULSATILE FLOW}

With continuous flow, the temperature-time curve declines exponentially after the maximum temperature difference has been reached, enabling the time at which temperature returns to the baseline value to be predicted from the slope of the earlier part of the curve. This may be advantageous since otherwise the correct calculation of the area of the tail of the curve is critically dependent on absence of fluctuation of baseline temperature. Since the estimation of the total area under the curve, and hence cardiac output per minute, is based on a time sample considerably shorter than a minute, the shorter the time-base of the calculation the larger the sampling error. This is of little moment if flow is continuous, but is potentially an important source of error when flow is discontinuous or pulsatile.

Pulsatile flow brings an additional problem: the concentration-time curve for the marker no longer shows a smooth exponential decline but is stepped in phase with systole. The damping of the response produced by use of a cuvette in dye dilution has the effect of smoothing the exponential curve, and this may be achieved electronically in the design of the thermistors used in thermodilution. Although theoretically a slightly delayed response of the marker detecting system should not alter the area under the curve, ${ }^{10}$ it has been found that use of a thermistor with a long time constant reduces the area and overestimates the flow rate. ${ }^{35}$ On the other hand, if the curve is inade- quately smoothed, estimation of the mean rate of exponential decline is subject to considerable error.

The mathematical validity of thermodilution as a method of calculating cardiac output when flow is pulsatile depends on absence of overlap between the frequency spectra of flow (determined principally by the heart rate) and the process of mixing and thermodilution. ${ }^{36}$ Theoretically, the error due to pulsatility is small, but theory indicates a particular susceptibility to low frequency fluctuations in flow rate, such as are associated with respiration, and this has been found in practice. ${ }^{37}$

Our circulation model permits comparison between measurements of continuous and pulsatile flow. The roller pump we used closely simulates naturally occurring pulsatile flow, as judged by the similar appearances of the Doppler ultrasound recordings in vitro and in vivo. ${ }^{38}$ In all three cardiac output computers accuracy and variability were significantly worse with pulsatile than with continuous flow. The pooled result of the predicted measurement at a continuous flow rate of 5 litres per minute was 5.6 (1.1) litres per minute and that during pulsatile flow was $8 \cdot 1(1 \cdot 2)$ litres per minute. The explanation for this overestimation during pulsatile flow is unlikely to be a greater loss of indicator from the circulation since any temperature differential within and without the circulation is unlikely to be altered by the pattern of flow within it. Pulsatile flow might increase the degree of mixing of the indicator, but this would only cause an increase in the estimation of pulsatile relative to continuous flow if mixing with continuous flow was inadequate. This seems unlikely since with continuous flow both reproducibility and accuracy were better than with pulsatile flow. Error in the calculation of the area under the temperature-time curve is almost certainly the main source of inaccuracy with pulsatile flow. A slow thermistor response may contribute to this inaccuracy, and sampling error is another possible factor.

With pulsatile flow, correct estimation of flow per minute is only possible if the indicator dilution curve that comprises the time sample is equivalent to a whole number of pump cycles. If the time sample always starts with systole or a period of rapid flow and is not an exact number of pump cycles then average flow will be overestimated. Conversely, if the time sample starts with diastole or a period of stationary flow then average flow will be underestimated except when the time sample is an exact number of pump cycles. In our circulation model operation of the injectate pump was synchronised with the pressure wave in all measurements with pulsatile flow in order to minimise variability, but unwittingly reproduced the situation in which over- 
estimation of average flow is probable. If synchronisation has contributed to overestimation of flow rate, then injection of indicator randomly at any phase of the cardiac cycle, which is the case in clinical practice, will result in a substantial increase in variability though this will be accompanied by an improvement in accuracy.

The measurement of cardiac output by thermodilution is influenced by the low frequency fluctuation in flow rate caused by respiration, and it has been suggested that injection of the cold charge should be repeated at intervals throughout the respiratory cycle since the phase relation between ventilation and flow rate is inconstant. ${ }^{37}$ The potential for variation of the measurement as cardiac and respiratory cycles interact is considerable.

\section{INJECTATE VOLUME}

Bilfinger et al claimed that in vitro neither the temperature nor volume of injectate had any effect on the results from an Edwards cardiac output computer, ${ }^{2}$ but using a computer of different make Elkayam et al showed that a $10 \mathrm{ml}$ injectate resulted in less variability than either a $5 \mathrm{ml}$ or $3 \mathrm{ml}$ one. ${ }^{34}$

The volume of injectate used in thermodilution is a compromise. At one extreme a small volume leads to a temperature change that is lost in the fluctuation of baseline temperature. At the other extreme a large injectate volume will alter the flow rate (measurement of which is being attempted), will be incompletely mixed with blood flow, and will take an appreciable time to inject in relation to the mean transit time of blood from injection site to sensor. The net effect of increasing injectate volume on the accuracy and variability of thermodilution measurement is unpredictable and in our experiments it was different for each cardiac output computer. Because injectates of different volumes take different times to inject, the volume of injectate may alter the shape and duration of the temperature-time curve and hence alter the sample time, and this may explain why injectate volume has a much greater effect on accuracy during pulsatile than during continuous flow.

\section{COMPUTATION OF AREA UNDER CURVE}

If the main source of error during pulsatile flow results from inaccuracies in computing the area under the temperature-time curve, then computers using similar methods of doing this are likely to give results more closely correlated with each other than with absolute flow or with a computer using a different method of calculating the area under the curve. Thus, the correlation between IL and Gould computers, which use the longest time samples, is closer than the correlation of either with the
Edwards computer which uses the shortest sampling time. Many of the errors in the indicator dilution method of determining cardiac output are common to both dye dilution and thermodilution. Comparison of thermodilution and dye dilution does not therefore constitute an adequate validation of either method.

\section{CONCLUSIONS}

Although it may be valid theoretically, thermodilution as a method of measuring cardiac output is riddled with compromises when flow is pulsatile. The injectate volume and temperature for optimum accuracy is different from that for optimum reproducibility, differs from computer to computer, and alters in different experimental or clinical situations.

Thermodilution has usually been validated against another indicator dilution technique which will be similarly susceptible to errors. Our experiments have shown that with pulsatile flow very little reliance can be placed on the absolute measurement of blood flow by thermodilution, and in two out of the three cardiac output computers tested there is a closer correlation with another computer than with absolute flow rate. Under optimum conditions in vitro the standard error of the prediction for a flow rate of 5 litres per minute is seldom less than 0.5 litres per minute or $10 \%$. Under clinical conditions and with the influence of respiration the error of the method is likely to be substantially in excess of this figure. Levitt and Replogle conclude that the overall biological error of any method of cardiac output measurement is $15-20 \%$, and thermodilution falls within that range. ${ }^{1}$ Thus, as a gold standard for comparison with newer methods of measuring cardiac output, thermodilution looks somewhat tarnished. ${ }^{39}$

We are grateful to Grampian Health Board for a research grant.

\section{References}

1 Levitt JM, Replogle RL. Thermodilution cardiac output: a critical analysis and review of the literature. f Surg Res 1979; 27: 392-404.

2 Bilfinger TV, Lin CY, Anagnostopoulos CE. In vitro determination of accuracy of cardiac output measurements by thermal dilution. $\mathcal{f}$ Surg Res 1982; 33: 409-14.

3 Snedecor GW, Cochran WG. Statistical methods. 7th ed. Iowa: The Iowa State University Press, 1980:166.

4 Guyton AC, Jones CE, Coleman TG. Circulatory physiology: cardiac output and its regulation. Philadelphia: WB Saunders, 1973.

5 Visscher MB, Johnsson JA. The Fick principles: 
analysis of potential errors in its conventional application. F Appl Physiol 1953; 5: 635-8.

6 Braunwald E, ed. Heart disease-a textbook of cardiovascular medicine. Philadelphia: WB Saunders, 1980.

7 Selzer A, Sudrann RB. Reliability of cardiac output in man by means of the Fick principle. Circ Res 1958; 6: 485-90.

8 Zierler KL. Theoretical basis of indicator-dilution methods for measuring flow and volume. Circ Res 1962; 10: 393-407.

9 Hosie KF. Thermal-dilution technics. Circ Res 1962; 10: 491-504.

10 Nitzan M, Weinreb A, Appelbaum A. Theoretical validation of the thermal dilution method for cardiac output determination. IEEE Trans Biomed Eng 1980; 27: 613-5.

11 Taylor SH, Shillingford JP. Clinical applications of Coomassie blue. Br Heart $\mathcal{F}$ 1959; 21: 497-504.

12 Hamilton WF, Riley RL, Attyah AM, et al. Comparison of the Fick and dye injection methods of measuring cardiac output in man. Am $\mathcal{F}$ Physiol 1948; 153: 309-21.

13 Reddy PS, Curtiss EI, Bell B, et al. Determinants of variation between Fick and indicator dilution estimates of cardiac output during diagnostic catheterisation. Fick $v$ dye cardiac outputs. $\mathcal{F}$ Lab Clin Med 1976; 87: 568-76.

14 Swan HJC, Ganz W, Forrester J, Marcus H, Diamond $\mathrm{G}$, Chonette D. Catheterisation of the heart in man with use of a flow directed balloon-tipped catheter. $N$ Engl f Med 1970; 283: 447-51.

15 Runciman WB, Ilsley AH, Roberts JG. Thermodilution cardiac output-a systematic error. Anaesth Intensive Care 1981; 9: 135-9.

16 Vliers ACAP, Oesburg B, Visser KR, Zijlstra WG. Choice of detection site for the determination of cardiac output by thermal dilution: the injection-thermistor catheter. Cardivasc Res 1973; 7: 133-8.

17 Woods M, Scott RN, Harken AH. Practical considerations for the use of a pulmonary artery thermister catheter. Surgery 1976; 79: 469-75.

18 Afonso S, Herrick JF, Youmans WB, Rowe GG, Crumpton $\mathrm{CW}$. Temperature variations in the venous system in dogs. Am $\mathcal{F}$ Physiol 1962; 203: 278-82.

19 Ganz W, Swan HJC. Measurement of blood flow by thermodilution. Am $\mathcal{F}$ Cardiol 1972; 29: 241-6.

20 Ganz W, Donoso R, Marcus HS, Forrester JS, Swan HJC. A new technique for measurement of cardiac output by thermodilution in man. Am $\mathcal{F}$ Cardiol 1971; 27: 392-6.

21 Berger RL, Weisel RD, Vito L, Dennis RC, Hechtman HB. Cardiac output measurement by thermodilution during cardiac operations. Ann Thorac Surg 1976; 21: 43-7.

22 Kohanna FH, Cunningham JN. Monitoring of cardiac output by thermodilution after open-heart surgery. $\mathcal{f}$ Thorac Cardiovasc Surg 1977; 73: 451-7.

23 Mathur M, Harris EA, Yarrow S, Barrett-Boyes BG. Measurement of cardiac output by thermodilution in infants and children after open-heart operations. $\mathcal{Y}$ Tho- rac Cardiovasc Surg 1976; 72: 221-5.

24 Olsson B, Pool J, Vandermoten P, Varnauskas E, Wassen $\mathbf{R}$. Validity and reproducibility of determination of cardiac output by thermodilution in man. Cardiology 1970; 55: 136-48.

25 Weisel RD, Berger RL, Hechtman HB. Measurement of cardiac output by thermodilution. $N$ Engl $f$ Med 1975; 292: 682-4.

26 Hodges M, Downs JB, Mitchell LA. Thermodilution and Fick cardiac index determinations following cardiac surgery. Crit Care Med 1975; 3: 182-4.

27 Wyse SD, Pfitzner J, Rees A, Lincoln JCR, Branthwaite MA. Measurement of cardiac output by thermal dilution in infants and children. Thorax 1975; 30: 262-5.

28 Fischer AP, Benis AM, Jurado RA, Seely E, Teirstein $P$, Litwak RS. Analysis of errors in measurement of cardiac output by simultaneous dye and thermal dilution in cardiothoracic surgical patients. Cardiovasc Res 1978; 12: 190-9.

29 Sanmarco ME, Philips CM, Marquez LA, Hall C, Davila JC. Measurement of cardiac output by thermal dilution. Am f Cardiol 1971; 28: 54-8.

30 Powner DJ, Snyder JV. In vitro comparison of six commercially available thermodilution cardiac output systems. Med Instrum 1978; 12: 122-7.

31 Shellock FG, Riedinger MS. Reproducibility and accuracy of using room-temperature $v s$ ice-temperature injectate for thermodilution cardiac output determinations. Heart Lung 1983; 12: 175-6.

32 Shellock FG, Riedinger MS, Bateman TM, Gray RJ. Thermodilution cardiac output determinations in hypothermic postcardiac surgery patients: room vs ice temperature injectate. Crit Care Med 1983; 11: 668-70.

33 Woog RH, McWilliam DB. A comparison of methods of cardiac output measurement. Anaesth Intensive Care 1983; 11: 141-6.

34 Elkayam U, Berkley R, Azen S, Weber L, Geva B, Henry WL. Cardiac output by thermodilution technique. Effect of injectate's volume and temperature on accuracy and reproducibility in the critically ill patient. Chest 1983; 84: 418-22.

35 Meisner H, Hagl S, Heimish W, et al. Evaluation of the thermodilution method for the measurement of cardiac output after open-heart surgery. Ann Thorac Surg 1974; 18: 504-15.

36 Scheuer-Lesser, Morguet A, Reul H, Irnich W. Some aspects to the pulsation error in blood-flow calculations by indicator-dilution techniques. Med Biol Eng Comput 1977; 15: 118-23.

37 Snyder JV, Powner DJ. Effects of mechanical ventilation on the measurement of cardiac output by thermodilution. Crit Care Med 1982; 10: 677-81.

38 McLennan FM, Haites NE, Mackenzie JD, Danie MK, Rawles JM. Reproducibility of linear cardiac output measurement by Doppler ultrasound alone. $\mathrm{Br}$ Heart $\mathcal{f}$ 1986; 55: 25-31.

39 Schuster AH, Nanda NC. Doppler echocardiographic measurement of cardiac output: comparison with a non-golden standard. Am $\mathcal{F}$ Cardiol 1984; 53: 257-9. 